\title{
XI CONGRESO INTERNACIONAL DE FILOSOFÍA MEDIEVAL. PORTO, 26-31 AGOSTO, 2002.
}

Ha tenido Iugar en la ciudad de Porto, en la semana del 26 al 31 de agosto, el XI Congreso Internacional de Filosofía Medieval. Organizado por La Société Internationale pour l'Étude de la Philosophie Médiévale (SIEPM), y por el Gabinete de Filosofía Medieval de la Facultad de Letras de la Universidad de Porto. Ha contado también con la colaboración de numerosas instituciones y entidades financieras de Portugal.

Ha reunido a especialistas de los cinco continentes, que con sus intervenciones han puesto de manifiesto la vitalidad e importancia de la filosofía medieval, así como el encuentro de culturas muy distintas. El tema general que ha unificado los distintos trabajos e investigaciones ha sido: «Intelecto e imaginación en la filosofía medieval». Como afirmó la profesora Pacheco en la sesión inaugural, este tema presenta una gran riqueza filosófica en la economía global de la historia de la filosofía medieval e incluso contribuye a la propia especificidad de la filosofía medieval en cuanto tal, en el sentido que, en su significación más amplia, la teorización de las dos facultades del alma abre las vías de la tematización posterior de dos grandes corrientes filosóficas: por una parte, la relación del hombre con Dios y por lo tanto con el Ser, que nos coloca en el corazón del discurso metafísico medieval; por otra parte, la relación del hombre con el mundo y lo sensible, relación en la cual la imaginación juega a menudo un papel esencial de mediación en el cuadro de la percepción del mundo.

El programa del congreso se ha articulado a través de sesiones plenarias, sesiones de comisiones de trabajo de la SIEMP, y secciones de comunicaciones. Al finalizar se celebró la asamblea general donde se dio lectura al resumen de las actividades realizadas en los últimos 5 años y se procedió a la renovación de algunos cargos del Bureau. En total, a lo largo de estos días se celebraron 16 sesiones plenarias y 80 secciones temáticas donde se dieron lecturas aproximadamente a 250 comunicaciones.

Las sesiones del congreso tuvieron dos sedes. Por la mañana, las sesiones plenarias se realizaron en el Seminario de Vilar y por la tarde las secciones de comunicaciones en la Facultad de Letras.

Cuestiones como el proceso del conocimiento, la relación entre conocimiento y certeza, el pensamiento y la acción, los conimbricenses, la antropología del conocimiento, los límites del intelecto y la imaginación y el arte, fueron los temas que ocuparon las distintas intervenciones de las sesiones plenarias, en las cuales dos representantes españoles de reconocido prestigio ofrecieron unas magníficas intervenciones. El Profesor D. Joaquín Lomba, de la Universidad de Zaragoza, que habló de «Razón e imaginación en la Estética Musulmana Medieval» y D. José Luis Fuertes de la Universidad de Salamanca que intervino con una conferencia sobre «La escolástica del Barroco: Presencia del «Cursus Conimbricensis» en el «Pharus Scientiarum»(1659) de Sebastián Izquierdo.

Las sesiones plenarias ofrecieron el marco en el que se desarrollaron las secciones de comunicaciones sobre los más variados temas. Allí se reunieron investigadores veteranos y otros más jóvenes que tuvieron la ocasión de aprender de ellos. Los espacios destinados al diálogo después de cada comunicación fueron ocasión propicia para suscitar preguntas que marcarán en muchos casos el inicio de otros estudios. La pluralidad de puntos de vista ante una misma cuestión puso de manifiesto la variedad de líneas de investigación y de soluciones a los distintos problemas que allí se trataron. En este sentido, sirva de ejemplo y sin hacer injusticia a las otras intervenciones, la sesión del día 30 en la que dos visiones de la filosofía política de Tomás de Aquino se dieron cita con los profesores F. Bertelloni de Buenos Aires y el Profesor L. De Boni de Porto Alegre. El debate suscitado por el profesor Saranyana dio lugar a un interesante diálogo en el que los dos profesores pudieron exponer con amplitud sus respectivos puntos de vista. Las distintas comunicaciones que trataron sobre el pensamiento de Cusa o de Agustín propiciaron debates similares. Esta pluralidad responde a una razón más profunda que entronca con la misma naturaleza de los temas estudiados. La pluralidad de traducciones e interpretaciones que sobre el De anima han circulado desde los comienzos han cualificado las distintas escuelas y tendencias, que justifican los distintos estudios. A esto se une que los temas tratados se han podido abordar desde disciplinas muy distintas como la lógica, la semántica, la hermenéutica, la antropología o la metafísica.

Desde el punto de vista organizativo es preciso señalar en esta crónica el trabajo realizado por la Dra. Dña. Cándida Pacheco, de la Universidad de Porto, presidente de la comisión organizadora de este encuentro. Llevó sobre sí de un modo excelente, el peso de las arduas tareas organizativas, con las cargas económicas que todo congreso conlleva. Vaya este pequeño reconocimiento a ella y a todo el comité organizador: la Secretaria de la SIEMP, la comisión de la organización, el Centro Leonardo Coimbra de la Facultad de Letras de Porto y los miembros del Gabinete de Filosofía Medieval. 
Los actos extraacadémicos que se ofrecieron a los participantes del congreso fueron: una recepción ofrecida por el Ayuntamiento de Porto, el Banquete en la Alfandega y las excursiones a distintos lugares, como Coimbra, el paseo en barco por el Duero o la visita al centro histórico de la ciudad y a las bodegas.

Sobre el marco geográfico que albergó el congreso, deseo señalar que el origen de Porto está unido a la colina de la Sé llamada Morro da Sé, que da al río Duero, donde han sido identificados restos de un pequeño poblado proto-histórico. La Romanización aportó un gran desarrollo a la ciudad que fue elevada al estatuto de diócesis durante el período visigodo. La ciudad sufrió grandes retrocesos a causa de las invasiones árabes; el territorio fue reconquistado por Vímara Peres al final del siglo IX. Dña. Teresa, madre del primer Rey de Portugal, donó la tierra de Porto al Obispo D. Hugo que le proporcionó su primera carta foral en 1123. El desarrollo de la actividad comercial condujo a la urbanización progresiva de la zona situada en la ribera del río; en la segunda mitad del siglo XIV la ciudad fue rodeada de una segunda muralla. El comercio con el exterior creció no sólo en la dirección de los puertos nórdicos sino igualmente en el Mediterráneo.

Como he dicho al comienzo, el penúltimo día del congreso tuvo lugar la asamblea general donde se dio lectura al trabajo quinquenal de la sociedad y se procedió a la votación de los nuevos cargos. Fruto de las votaciones que se llevaron a cabo resultó elegida la profesora J. Hamesse como Presidente de la Sociedad, y el profesor Puig Montada, de España, como uno de los Vice-presidentes. Por último, los profesores Carvalho de Coimbra y Kiyewska de Lublín se han incorporado como nuevos vocales. La profesora Hamesse recalcó en su intervención el carácter familiar de la sociedad, que preside los encuentros y marca el estilo de las intervenciones. No cabe duda que ella ha contribuido a que sea así y cabe esperar que ese mismo talante esté presente en su trabajo durante el próximo mandato.

El XI Congreso Internacional terminó con una celebración inter-religiosa en el salón de actos de la Facultad de Filosofía. Participaron las primeras autoridades religiosas de todas las confesiones presentes en Porto: judíos, musulmanes, ortodoxos griegos, evangélicos luteranos, anglicanos, metodistas, baptistas y católicos. La plegaria, el canto y la fraternidad fue un feliz remate de este XI Congreso Internacional de Filosofía Medieval.

M S. Fernández-García

Universidad de Burgos

Facultad de Humanidades y Educación

Villadiego $s / n$ 09001, BURGOS

E-mail: sofer@ubu.es 